\title{
Diversity of gastrointestinal parasites in captive and domestic birds from zoological parks and one rural locality of Algeria
}

\author{
AbdElkarim Laatamna ${ }^{\prime *}$, Houssem Samari ${ }^{2}$, Yacine Chebhi $^{2}$ \& Lotfi Betal ${ }^{2}$ \\ ${ }^{1}$ Faculty of Nature and Life Sciences, University of Djelfa, Moudjbara Road, BP 3117, Djelfa, Algeria \\ ${ }^{2}$ Higher National Veterinary School, Issad Abbes Street, El-Alia, Algiers, Algeria \\ *Corresponding author: e-mail: laatamnaabdelkarim@yahoo.com
}

\begin{abstract}
Microscopic examination of 84 fresh fecal samples of 11 different species of birds from three zoological parks and one rural locality from Algiers and the Setif province (central-eastern of Algeria) indicated an overall prevalence of gastro-intestinal parasites 19\% (16/84). Overall, genera of Cryptosporidium Tyzzer, 1907, Eimeria Schneider, 1875, Capillaria Zeder, 1800, and larvae of strongyles type were recorded with prevalence of $6 \%, 4.8 \%, 3.6 \%$, and $4.8 \%$ respectively. Protozoa of Cryptosporidium was found only in ostrich (31.2\%), whereas, Eimeria spp. was observed in pigeons (40\%), hens (20\%) and ring-necked pheasants (14.3\%). Larvae of strongyles were recorded in mallards $(11.1 \%)$, emus $(14.3 \%)$ and peacocks $(9.1 \%)$, whereas, eggs of Capillaria was detected only in peacocks $(27.3 \%)$. No mixed infection was recorded in infected birds. Parasite fauna infecting the digestive tract of birds from Algerian zoological parks is a little diversified. Further studies should be carried out to better show the diversity of gastro-intestinal parasites of wild and domestic birds in Algeria across exhaustive studies covering many regions.
\end{abstract}

KEY WORDS Algeria; wild and domestic birds; gastro-intestinal parasites.

Received 12.04.2019; accepted 29.08.2019; published online 20.09.2019

\section{INTRODUCTION}

Many species of wild birds are kept in captivity in zoological gardens to preserve the biodiversity and for scientific and educative purposes. This change in life pattern exposes birds to the risk of contracting various parasitic infections including gastro-intestinal parasites. The effects of gastro-intestinal parasitic infections are well known in domesticated birds, leading to economic losses related to a decrease in productivity and performance as well as high mortality. These effects remain ambiguous both in wild animals in freedom and in captive birds (Wobeser, 2009), certainly affecting the growth and reproduction of the latter (Pérez Cordón et al., 2009). (Pérez Cordón et al., 2009). Several genera of protozoa and helminthes were reported in different bird species of zoological gardens in different countries (Carrera-Játiva et al., 2018), but data on prevalence and epidemiology of parasite transmission remain a bit scarce (Pérez Cordón et al., 2009; Carrera-Játiva et al., 2018).

In Algeria, little is available on prevalence and diversity data of gastro-intestinal parasites infecting captive birds in the different zoological parks. Marniche et al. (2017) identified nine genera of protozoa and helminthes in captive Pavo cristatus (Linnaeus, 1758). Yousfi et al. (2013) and Temimi et al. (2017) have found the same situation in freerange wild birds and domestic birds reared tradi- 
tionally in rural areas. Therefore, the present study was designed to investigate the prevalence and diversity of gastro-intestinal parasites in captive and domestic birds from three zoological parks and one rural locality in central and eastern Algeria. For this purpose, fecal samples from different bird species were subjected to coproscopic examination.

\section{MATERIAL AND METHODS}

The present study was carried out between January and April 2015 in the zoo parks of Ben-Aknoun and El-Hamma located in the capital Algiers, and a zoo park and one rural locality from the province of Setif in eastern Algeria. Eighty-four fecal samples were collected from 11 different species of captive and domestic birds (Table 1). The birds of the zoological parks were housed in captivity in an aviary with a concrete floor, ostriches were kept on soil, the mallard and goose are kept in water pools. In the rural area, hens and mallard were raised traditionally, living in free-range. Fresh feces were obtained directly from the ground immediately after defecation of birds and each sample was individually placed into a sterile plastic container, labeled with the host data (mainly bird species) and transported in an isotherm box to the laboratory.

Samples were subjected to macroscopic observation to assess the quality of the feces and to check for visible parasitic elements. Fecal samples were processed for microscopic examination by using formalin-ether sedementation (Allen \& Ridley, 1970). The research of Cryptosporidium species was done by aniline-carbol-methyl violet staining (Miláček \& Vítovec, 1985).

\section{RESULTS}

Overall, microscopic examination revealed that $16 / 84(19 \%)$ of birds $(16 / 74 ; 21.6 \%$ in captive birds and $0 / 10 ; 0 \%$ in domestic birds) have been to be positive at least to eggs or oocysts of one genus of gastro-intestinal parasites. Protozoan infections were seen in $9 / 84(10.7 \%)$, whereas helminth infections were seen in $7 / 84(8.3 \%)$. Occurrence of infection has been found in the zoological park of Ben Aknoun (14/42), followed by that of El-Hamma (2/20).
No infected birds were recorded in the zoo and rural area of Setif. Overall, genera of Cryptosporidium Tyzzer, 1907, Eimeria Schneider, 1875, Capillaria Zeder, 1800, and larvae of strongyles type were recorded with prevalence of $6 \%, 4.8 \%, 3.6 \%$, and $4.8 \%$ respectively. Cryptosporidium sp. was found only in ostriches (Struthio camelus) $(5 / 16 ; 31.2 \%)$ and four isolates were previously characterized genetically as Cryptosporidium baileyi Current, Upton et Haynes, 1986 (Laatamna et al., 2017). Eimeria sp. was recorded in pigeons (Columba livia) $(2 / 5$; $40 \%$ ), a hen (Gallus gallus) $(1 / 5 ; 20 \%)$ and a ringnecked pheasant (Phasianus colchicus) (1/7; $14.3 \%$ ). Larvae of strongyles were observed in mallards (Anas platyrhynchos) $(2 / 18 ; 11.1 \%)$, an emu (Dromaius novaehollandiae) $(1 / 7 ; 14.3 \%)$ and a peacock (Pavo sp.) (1/11; 9.1\%), whereas, eggs of Capillaria sp. were detected only in peacocks (3/11; $27.3 \%$ ) (Table 1). No mixed infection was recorded in infected birds.

\section{DISCUSSION}

Little is known on the composition and diversity of gastro-intestinal parasitic infections in wild, captive and domestic birds in Algeria. Results of the present study reported an overall infection rate of $19 \%(16 / 84)$ of investigated birds at zoological parks and one rural locality of capital Algiers and Setif province. These findings are in agreement with those reported previously from Nigeria (Otegbade \& Morenikeji, 2014). Contrasting results reported an overall prevalence higher than one of the this survey (Parsani et al., 2001; Pérez Cordón et al., 2009; Papini et al., 2012; El-Shahawy \& Abou Elenien, 2015; Akram et al., 2019) coming up to $100 \%$ (Yousfi et al., 2013; Hoque et al., 2014; Edosomwan \& Igetei, 2018).

The parasitic infections of captive birds are likely to depend on host species, husbandry factors including hygienic conditions, feeding and population density in the aviary where these birds live. In domestic birds kept in free-range, environmental conditions and traditional breeding are important factors exposing birds to multiple contaminations. Otegbade \& Morenikeji (2014) and Gurler et al. (2010) also reported a low parasite diversity. In contrast, the parasite fauna infecting the digestive tract of captive and domestic birds was much diversified 
in several surveys worldwide (Faust \& Pappas, 1977; Papini et al., 2012; El-Shahawy \& Abou Elenien, 2015; Carrera-Játiva et al., 2018; Edosomwan \& Igetei, 2018; Akram et al., 2019). Cryptosporidium, Eimeria, Capillaria and larvae of strongyles were seen with prevalence of $6 \%, 4.8 \%, 3.6 \%$, and $4.8 \%$, respectively. In Algeria, Marniche et al. (2017) revealed a higher infection rate of Eimeria and Capillaria in Pavo cristatus from the zoological parks of Ben Aknoun and El-Hamma. Protozoan of Cryptosporidium and Eimeria were reported as the most important parasites isolated in captive birds from Egypt (El-Shahawy \& Abou Elenien, 2015). It is evident that Eimeria is frequently identified in wild, captive and domestic birds. Cryptosporidiosis is considered as one of the most prevalent parasitic infections in domestic, captive and wild birds worldwide and its prevalence varies according to host species and reported studies. Nematodes of the Capillarid, including Capillaria genus, can infect a large spectrum of birds and cause, in case of high intensity of infection, a clinical disease associated with emaciation, anorexia and diarrhea (Yabsley, 2009). Capillaria eggs were identified in captive birds with an infection rate of $5.6 \%, 11.41 \%, 10 \%, 14.1 \%$ in Egypt, Pakistan, Spain and Nigeria respectively, and considered as the most prevalent gastro-intestinal parasite in these last two reports (Pérez Cordón et al., 2009; Otegbade \& Morenikeji, 2014; El-Shahawy \& Abou Elenien, 2015; Akram et al., 2019). In northwestern Algeria, adult forms of Capillaria species were identified in domestic hens, with predominance of Capillaria caudinflata Molin, 1858 (Yousfi et al., 2013). Compared to the findings of this study, Papini et al. (2012) noted a slightly higher prevalence of eggs excretion of strongyles in zoo birds from Italy. Strongyles are very diversified, common to other animals and considered the most excreted parasites by different species of captive birds from Bristol Zoo Gardens in USA (Carrera-Játiva et al., 2018). Reported data on prevalence of gastro-intestinal parasites in captive birds remain different across many studies worldwide. This survey showed low diversity of gastrointestinal parasites in Algerian captive birds in comparison with that reported in most studies cited previously. However, we did not attempt to discuss

\begin{tabular}{|c|c|c|c|c|}
\hline \multirow{2}{*}{ Avian species } & \multicolumn{4}{|c|}{ Number of examined birds, number of infected birds and identified genera } \\
\hline & Zoo Ben Aknoun & Zoo garden El-Hamma & Zoo Setif & Rural area of Setif \\
\hline $\begin{array}{l}\text { Gallus gallus domesticus } \\
\text { (Linnaeus, 1758) (Chicken) }\end{array}$ & $\begin{array}{c}\mathbf{3} \\
\text { Eimeria }(\mathrm{n}=1)\end{array}$ & - & - & 2 \\
\hline $\begin{array}{l}\text { Columba livia domestica Gmelin, } \\
1789 \text { (Domestic pigeon) }\end{array}$ & $\begin{array}{c}\mathbf{3} \\
\text { Eimeria }(\mathrm{n}=2)\end{array}$ & - & 2 & - \\
\hline $\begin{array}{l}\text { Eclectus roratus (Müller, 1776) } \\
\text { (Eclectus parrot) }\end{array}$ & 5 & 2 & - & - \\
\hline $\begin{array}{l}\text { Anas platyrhynchos } \\
\text { Linnaeus, } 1758 \text { (Mallard) }\end{array}$ & $\begin{array}{c}\mathbf{6} \\
\text { Strongyles larvae }(n=2)\end{array}$ & 2 & 2 & 8 \\
\hline $\begin{array}{l}\text { Anser anser (Linnaeus, 1758) } \\
\text { (Greylag goose) }\end{array}$ & - & - & 2 & - \\
\hline $\begin{array}{l}\text { Phasianus colchicus Linnaeus, } \\
1758 \text { (Common pheasant) }\end{array}$ & $\begin{array}{c}\mathbf{2} \\
\text { Eimeria }(\mathrm{n}=1)\end{array}$ & 3 & 2 & - \\
\hline Pavo sp. (Peacock) & $\begin{array}{c}\mathbf{3} \\
\text { Capillaria }(\mathrm{n}=1) \\
\text { Strongyles larvae }(\mathrm{n}=1)\end{array}$ & $\stackrel{\mathbf{6}}{\text { Capillaria }(\mathrm{n}=2)}$ & 2 & - \\
\hline $\begin{array}{l}\text { Dromaius novaehollandiae } \\
\text { (Latham, 1790) (Emu) }\end{array}$ & $\begin{array}{c}\mathbf{3} \\
\text { Strongyles larvae }(\mathrm{n}=1) \\
\end{array}$ & 3 & 1 & - \\
\hline $\begin{array}{l}\text { Struthio camelus Linnaeus, } 1758 \\
\text { (Ostrich) }\end{array}$ & $\begin{array}{c}\mathbf{1 3} \\
\text { Cryptosporidium }(\mathrm{n}=5)\end{array}$ & 2 & 1 & - \\
\hline $\begin{array}{l}\text { Numida meleagris (Linnaeus, } \\
\text { 1758) (Helmeted guineafowl) }\end{array}$ & - & 2 & - & - \\
\hline $\begin{array}{l}\text { Balearica pavonina (Linnaeus, } \\
\text { 1758) (Black crowned crane) }\end{array}$ & 4 & - & - & - \\
\hline
\end{tabular}

Table1. The different species of birds sampled in the present study and identified gastro-intestinal parasites. 
the prevalence of each parasite in each bird species, which is certainly variable according to the type of involved parasite and hostbird species. In order to show more data on prevalence, parasite diversity and transmission epidemiology of gastro-intestinal parasites in captive birds from zoological parks and domestic birds raised traditionally in rural areas, further studies should be carried out across exhaustive surveys covering most of the provinces of the country.

\section{ACKNOWLEDGEMENTS}

The authors would like to thank the responsible veterinarians of Zoological parks of Algiers and Setif provinces for their help on material sampling.

\section{REFERENCES}

Akram M.Z., Zaman M.A., Jalal H., Yousaf S., Khan A.Y., Farooq M.Z., Rehaman T.U., Sakandar A., Qamar M.F. \& Bowman D.D., 2019. Prevalence of gastrointestinal parasites of captive birds in Punjab, Pakistan. Pakistan Veterinary Journal, 39: 132-134.

Allen V.H. \& D.S. Ridley., 1970. Further observations on the formol-ether concentration technique for faecal parasites. Journal of Clinical Pathology, 23: 545-546.

Carrera-Játiva P.D., Morgan E.R., Barrows M. \& Wronski T., 2018. Gastrointestinal parasites in captive and free-ranging birds and potential cross-transmission in a zoo environment. Journal of Zoo and Wildlife Medicine, 49: 116-128.

Edosomwan E.U. \& Igetei E.J., 2018. Ecto and endo parasites of domestic birds in Owan West, East and Akoko-Edo in Edo State of Nigeria. Annals of Reviews and Research, 4: 555629.

El-Shahawy I.S. \& Abou Elenien F., 2015. Enteric parasites of Egyptian captive birds: A general coprological survey with new records of the species. Tropical Biomedicine, 32: 650-658.

Faust B.S. \& Pappas P.W., 1977. A survey of coccidia and helminth parasites of birds at the Columbus (Ohio) zoo. The Journal of Zoo Animal Medicine, 8: 18-23.

Gurler A.T., Beyhan Y.E., Acici M., Bolukbas C.S. \& Umur S., 2010. Helminths of mammals and birds at the Samsun zoological garden, Turkey. Journal of Zoo and Wildlife Medicine, 41: 218-223. https:// doi.org/10.1638/2009-0070R1.1

Hoque M.A., Hassan M.M., Haque E., Shaikat A.H., Khan S.A., Alim A., Skerratt L.F., Islam A., Tun
H.M., Dissanayake R., Day T.K., Debnath N.C. \& Yamage M., 2014. A survey of gastro-intestinal parasitic infection in domestic and wild birds in Chittagong and Greater Sylhet, Bangladesh. Preventive Veterinary Medicine, 117: 305-312.

Laatamna A.K., Holubová N., Sak B. \& Kváč M., 2017. Cryptosporidium meleagridis and C. baileyi (Apicomplexa) in domestic and wild birds in Algeria. Folia Parasitologica, 64: 018. https://doi.org/10. 14411/fp.2017.018

Marniche F., Milla A., Dik B., Laloui F., Medkour M., Nadjai B., Noumi H. \& Zerouki S., 2017. Parasites encountered in captivity birds: case of infested blue peacock - Pavo cristatus Linnaeus, 1758 (Aves: Phasianidae) in different localities from Algeria. Muzeul Olteniei Craiova. Oltenia. Studii şi comunicări. Ştiinţele Naturii, 33, 79-84.

Miláček P. \& Vítovec J., 1985. Differential staining of cryptosporidia by aniline-carbol-methyl violet and tartrazine in smears from feces and scrapings of intestinal mucosa. Folia Parasitologica, 32: 50.

Otegbade A.C. \& Morenikeji O.A., 2014. Gastrointestinal parasites of birds in zoological gardens in southwest Nigeria. Tropical Biomedicine, 31: 54-62.

Papini R., Girivetto M., Marangi M., Mancianti F. \& Giangaspero A., 2012. Endoparasite infections in pet and zoo birds in Italy. The Scientific World Journal, Volume 2012, Article ID 253127.

Parsani H.R., Momin R.R. \& Bhuva C.N., 2001. Parasitic infections among captive birds at Sakkarbagh zoo, Junagadh, Gujarat. Zoo's Print Journal, 16: 462-464.

Pérez Cordon G., Hitos Prados A., Romero D., Sánchez Moreno M., Pontes A., Osuna A. \& Rosales M.J., 2009. Intestinal and haematic parasitism in the birds of the Almunecar (Granada, Spain) ornithological garden. Veterinary Parasitology, 165: 361-366.

Temimi I., Marniche F., Lazli A., Milla A. \& Dik B., 2017. The study of the parasites of the bird Egretta garzetta (Linnaeus, 1766) (Aves: Ardeidae) in northeastern wetlands of Algeria. Muzeul Olteniei Craiova. Oltenia. Studii şi comunicări. Ştiinţele Naturii, Tom. 33: No. 1.

Wobeser G.A., 2009. Introduction. In: Atkinson C.T., Thomas N.J. \& Hunter D.B. (Eds.), Parasitic Diseases of Wild Birds. John Wiley \& Sons, Oxford, UK, pp. 3-9.

Yabsley M.J., 2009). Capillarid Nematodes. In: Parasitic Diseases of Wild Birds, Atkinson C.T., Thomas N.J. \& Hunter D.B. (Editors). John Wiley \& Sons, Oxford, UK, 463-497.

Yousfi F., Senouci K., Medjoual I., Djellil H. \& Hadj Slimane T., 2013. Gastrointestinal helminths in the local chicken Gallus gallus domesticus (Linnaeus, 1758) in traditional breeding of North-Western Algeria. Biodiversity Journal, 4: 229-234. 